UCRL-53641

Distribution Category UC-11

UCRL -53641

DE85 012835

\title{
ARAC Status Report: 1985
}

\author{
M. H. Dickerson \\ P. H. Gudiksen \\ T. J. Sullivan \\ G. D. Greenly
}

Manuscript date: May 1985

\section{DISCLAIMER}

This report was prepared as an account of work aponsored by an agency of the United States Government. Neither the United States Government nor any agency thereof, nor any of their employees, makes any warranty, express or implied, or assumes any legal liability or responsibility for the accuracy, completeness, or usefulness of any information, epparatus, product, or process oisclosed, or represents that its use would not infringe privately owined rights. Reference herein to any specific commercial product, process, or service by trade name, trademark, manufactur's, or otherwise does not necessarily constitute or imply its endorsenent, recommendation, Jr favoring by the United States Government or any agency thereof. The views and opinions of asthors expresued herein do not necessarily state or reflect those of the United States Government or any agency thereof.

\section{LAWRENCE LIVERMORE NATIONAL LABORATORY University of California - Livermore, California - 94550}




\section{Contents}

Introduction ........................ . . . . . . . . . . . . . ARAC Emergency Response Operating System . . . . . . . . . . . . 2 Assessment Methodology . . . . . . . . . . . . . . . . . . . . 4 ARAC Products . . . . . . . . . . . . . . . . . . . . 4 Requirements for Receiving the ARAC Service . . . . . . . . . . . 7 Organizations Receiving ARAC Services . . . . . . . . . . . . . . . . . 12 Future Directions . . . . . . . . . . . . . . . . . . . . . 13 Acknowledgment . . . . . . . . . . . . . . . . . . . . . . . . . 14 References . . . . . . . . . . . . . . . . . . . . 15 A ppendix A. Description of Operational Models . . . . . . . . . . . 17 MATHEW/ADPIC Model . . . . . . . . . . . . . 17 PATRIC Model . . . . . . . . . . . . . . . . . . 17 2BPUFF Model . . . . . . . . . . . . . . . 17 KDFOC2 . . . . . . . . . . . . . . . . . . 17 CPS Model . . . . . . . . . . . . . . . . . . . . . . . 18 IPS Model . . . . . . . . . . . . . . . . . . . . . . . 18 


\title{
ARAC Status Report: 1985
}

\begin{abstract}
The Atmospheric Release Advisory Capability is a real-time emergency-response service available to federal and state agencies for providing estimates of the environmental consequences of accidental releases of radioactivity into the atmosphere. This includes the estimation of radiation doses to nearby population centers and the levels and extent of surface contamination. The service is currently being expanded to support the emergency response plans at approximately 50 Department of Defense and Department of Energy fucilities. This expunsion consists of the installation of enhanced computational and data communications and processing systems, development of terrain and geographic data bases, improvements in modeling capabilities, as well as increased staff housing farilities. This report summarizes the current status of $\mathrm{ARAC}$ and the requirements to receive the service.
\end{abstract}

\section{Introduction}

The Atmospheric Release Advisory Capability (ARAC), which has been in existence for over eleven years, $\{1,2,3]$ is a real-time emergency response system designed to assess the potential environmental consequences of radiological accidents. It responds to a wide spectrum of atmospheric releases that may be associated with transportation accidents or accidents at Department of Energy and Department of Defense nuclear-capable facilities as well as nuclear power plants. It consists of communications and computer systems, data bases and verified atmospheric dispersion models, and an experienced assessment staff. A prototype operational system was developed and tested during the mid-1970s that permitted operations to begin on a $40 \mathrm{~h}$ per week basis in 1979. Following its response to the TMI accident in March 1979, the purge of krypton from the TMI containment in Juiy 1980 and the Titan II missile accident in Arkansas in September 1980, an expansion of the ARAC service was initiated by the Departments of Energy and Defense. This expansion includes new hardware and software for the system, increased staff, additional facilities for housing staff and compuiers, and expanded operational hours. Since its inception in 1974, ARAC has responded t/ $/$ over 80 real or potential events and major exercises.

The staff presently includes $2 \mathcal{E}$ scientists and technicians. Their background, training and experience ranges from transport and diffusion physics, weather forecasting, and health physics to electronics engineering and computer science. Approximately half of the staff is presently involved in operations while the remainder is devcted to computer systems development and maintenance, and model research and development. The experience level of many staff members in the area of emergency response for nuclear accidents is based on participation in responses to actual or potential releases plus major exercises over the past seven years. In addition to developing and implementing an expanded system, staff members are continually involved in the planning and execution of major exercises, briefings to various organizations, conducting classes on emergency response, and performing coordinating activities with several government agencies. 
This report describes the current status of the ARAC system, requirements for obtaining the service, the organizations related to the ARAC service, and future directions for the service. Even though the ARAC service is presently limited to radiological accidents, the fundamentals of the service as an emergency-response resource are applicable to toxic chemical releases as well.

\section{ARAC Emergency Response Operating System}

The ARAC operating system integrates data acquisition, data analysis, data-basing and management functions, and atmospheric transport and diffusion models to enable the ARAC staff to produce real-time assessments of accidental atmospheric releases of radioactivity. In order to support the emergency preparedness plans at the DOD nuclearcapable sites, the DOE nuclear facilities, and the NRC, the current expansion includes significant upgrades in computational, communications, and data-basing facilities as well as increased staff. The goals of this expansion are to

- Support up to 100 fixed sites.

- Simultaneously handle two emergency responses.

- Provide timely response to an accident at a "nonfixed" location.

- Automate manual data processing functions.

- Provide complete computer backup for the ARAC center.

The ARAC has traditionally used the Lawrence Livermore National Laboratory's central computing facility in conjunction with several minicomputers to perform a hazards assessment of a particular accident. The current expansion includes the installation of ARAC dedicated computers that will be used to perform the assessments. This consists of two dual-processor main computers that are linked with three front-end communications processors, two gigabytes of sharable disk storage, and a telecopier by means of a highspeed local-area communications network. This system, which has been named the ARAC Emergency Response Operating System (AEROS), will be able to interact directly over commercial telephone lines with the data communications terminal situated at each site and the Air Force Global Weather Central.[4]

The installation of the AEROS hardware has been completed, and a major fraction of the communications, graphics, and terrain and geographic data-base components has also been completed. The primary focus is presently on the extensive software that needs to be developed to automate the data acquisition, validation, and data-basing processes in order to optimize the speed of operation in a manner consistent with a reliable and accurate assessment. During the coming year a major effort will also be devoted to transferring the atmospheric dispersion models from the LLNL computer center to the AEROS. A structured software methodology was employed to enable the development staff of 25 computer scientists, meteorologists, health physicists, and engineers to progress simultaneously on several parts of the system development effort.[5] This technique ensures that system requirements are satisfied, and adequate documentation of the software will be available to permit future maintenance and upgrades. 
An integral part of the ARAC system is the site data communications system, hereafter referred to as the site system. It consists of a small professional computer equipped with three modems, a 10-megabyte hard disk, two floppy disk drives, color monitor, keyboard and printer. One of the modems is connected to the site meteorological tower, whereas the remaining two are used to communicate with the ARAC center: one for voice and the other for data transmissions.[6] The system's configuration is shown in Fig. 1. The principal purposes of the site system are to

- Permit site personnel to transmit meteorological and source term data to the ARAC nter.

- Receive and display ARAC assessments.

- Collect and display local meteorological data.

- Perform localized Gaussian dispersion model calculations.

- Transmit messages to and from the ARAC center.

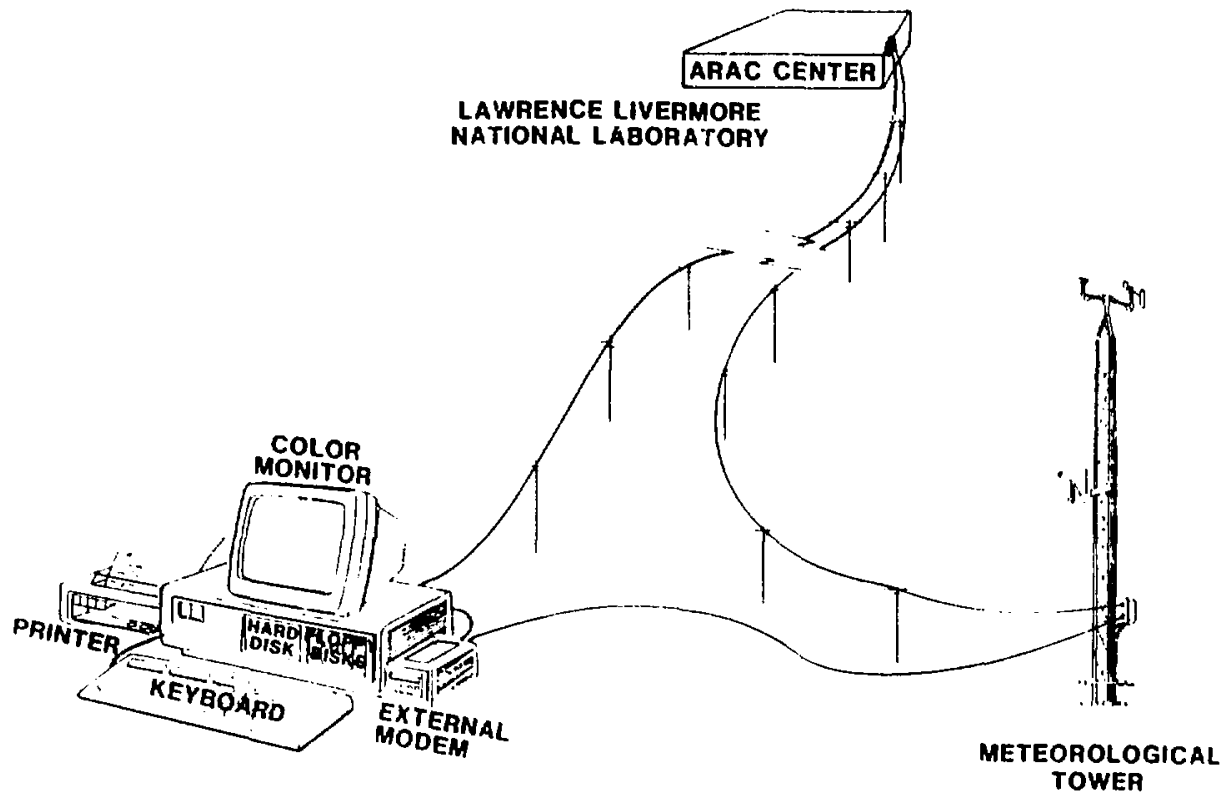

FIGURE 1. ARAC site system configuration.

The software for the site system, which has recently been completed, provides for automated processing and display of information during an emergency. Its features are focused on several menu choices that lead the user to standardized forms for data entry and displays. 


\section{Assessment Methodology}

Simulation is the active part of the ARAC project, i.e. the process of developing an assessment for an emergency, exercise or scenario development, that employs a summation of project elements. This includes the following:

1. The rapid acquisition of meteorological and source term data from the event site, meteorological data for the surrounding region from the Air Force (Ylobal Weather Central (AFGWC), and terrain information from the ARAC terrain data base.

2. Interpretation and quality-control checking of the data by means of computer generated graphics[7] that include pseudo three-dimensional terrain views (see Fig. 2).

3. Determination of key parameters, such as source term, atmospheric stability, mixing depth, and boundary layer depth.

Following these three steps model calculations are initiated and graphical displays of wind fields and plume trajectories become avuilable to the assessor to aid in the visualization and add to the quality control of the simulation. Finally, graphical displays of calculated dose contours and surface contamination levels overlaid on local area maps are produced for transmittal to the event site and appropriate emergency preparedness officials. Examples of ARAC products are described in the next section.

One of the primary goals of ARAC is to produce pertinent information for the emergency response manager in a timely and reliable manner. Thus, upon completion of the AEROS system, an initial qualitative assessment based on several simplifying assumptions will be available within 15 minutes after notification and a complete assessment, based upon the initial input conditions, will be available within 45 minutes after notification of an event at the supported sites, and within 90 minutes for any accident site within the continen;al U.S. Thereafter, ARAC will provide continuing support on an hourly basis until terminution of the emergency. For nonsupported sites very simple geographic background maps will be digitized in real time, whereas supported sites have the advantage of customized, detailed site maps. Currently, the graphical displays are transmitted via high speed telecopier. This mode of transmission, however, will be replaced by the use of the ARAC site system.

\section{ARAC Products}

The ARAC products include graphical projections (contour patterns) of the location and levels of surface contamination and the potential radiation dose to people in the area due to exposure to the resulting radioactive cloud. These projections are used by the initial radiological response force to aid in assessing the potential impact of the accident and to identify areas for initial investigation by the radiological survey teams.

Tuble 1 lists the atmospheric dispersion models that are presently used in the ARAC service. Appendix A provides a brief description of each model. The large scai, tobal models, 2BPUFF, a special version of PATRIC and the KDFOC fallout model, are used primarily for assessments associated with nuclear yields, e.g., atmospheric tests of nuclear weapons. The MATHEW/ADPIC, PATRIC and Gaussian [Continuous Point Source (CPS) and Instantaneous Point Source (IPS)] models are used for regional assessments, 


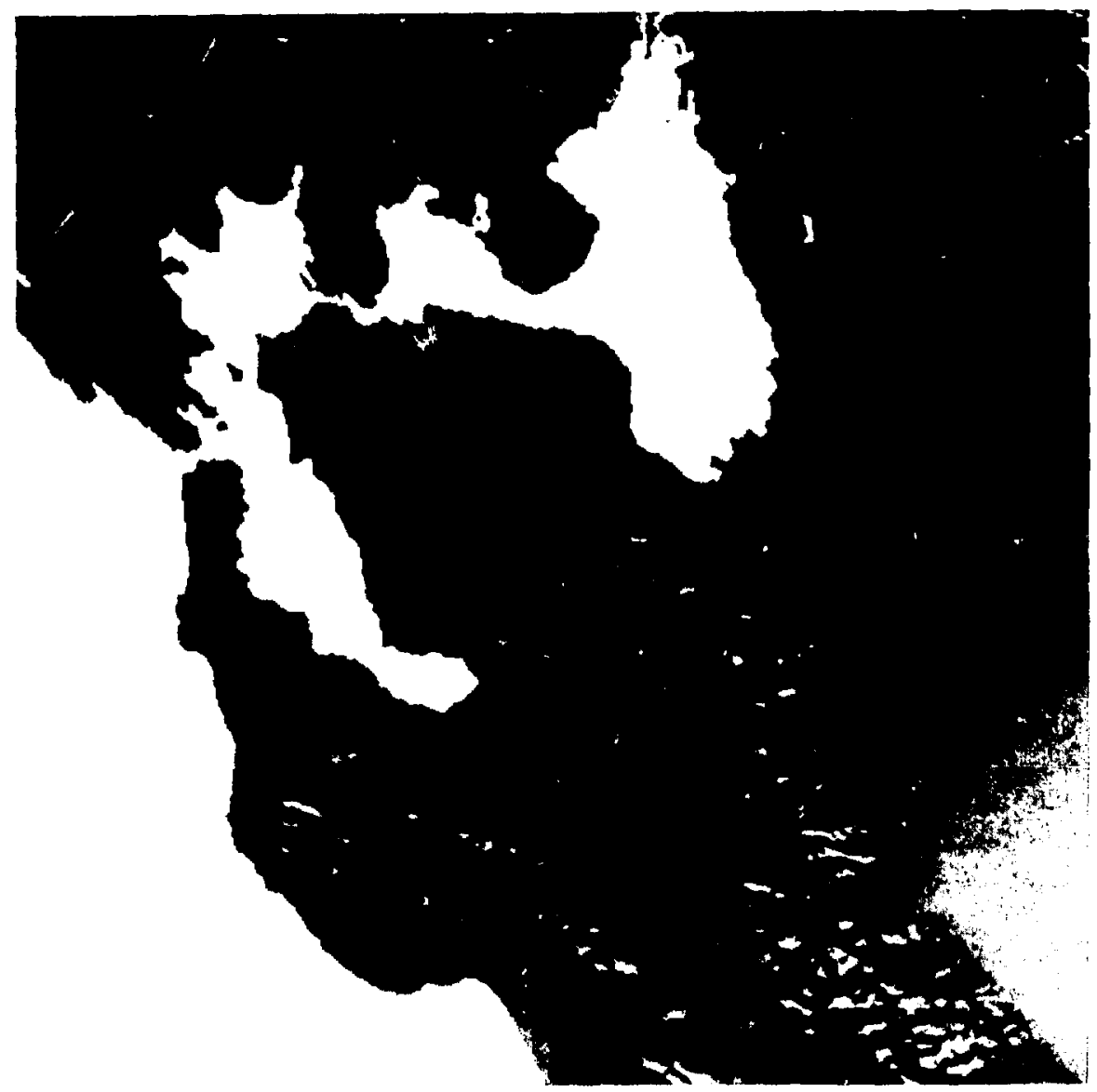

FlGURE 2. Graphical display of terrain data for the San Francisco Bay Area.

e.g., nuclear power plant accidents or nuclear weapons arcidents involving the high-explosive dispersal of radioactive material. Since the MATHEW/ ADPIC model is used for the majority of assessments, it will be used in this report to illustrate the ARAC products $[8,9,10]$ that may be generated in the unlikely event of a nuclear weapons accident at a military facility. Using a ficticious Air Force Base (Radnor) as the simulated accident location, the following sequence of even is would take place:

1. Notification of the National Military Conmand Center (NMCC).

2. Notification of ARAC.

3. Initial Gaussian IPS calculation-available within 2-3 minutes from the site system. 
TABLE 1. ARAC operational models.

\begin{tabular}{|c|c|c|c|c|}
\hline Model & $\begin{array}{c}\text { Global } \\
\text { Scale } \\
\sim 20,000 \mathrm{~km}\end{array}$ & $\begin{array}{c}\text { Synoptic } \\
\text { Scale } \\
\sim 2,000 \mathrm{~km}\end{array}$ & $\begin{array}{l}\text { Regional } \\
\quad \text { Scale } \\
\sim 200 \mathrm{~km}\end{array}$ & $\begin{array}{c}\text { Meso } \\
\text { Scale } \\
\sim 20 \mathrm{~km}\end{array}$ \\
\hline Simple & - & - & - & Gaussian \\
\hline Intermediate & 2BPUFF & 2BPUFF & $\begin{array}{c}\text { MATHEW/ADFIC } \\
\text { KDFOC2 }\end{array}$ & $\begin{array}{c}\text { MATHEW/ADPIC } \\
\text { KDFOC2 }\end{array}$ \\
\hline Complex & PATRIC & PATRIC & MATIIEW/ADPIC & MATIIEW/ADPIC \\
\hline
\end{tabular}

4. Initial ARAC calculation-available from the ARAC center within 15 minutes after notification.

5. Advanced ARAC calculation-available from the ARAC center within 45 minutes after notification.

Figure 3 illustrates the initial MATHEW/ADPIC calculation available to the Incident Response Force (IRF) on-scene commander from the ARAC center approximately $15 \mathrm{~min}$ utes after notification. This assessment assumes that all of the plutonium involved in the accident was aerosolized according to high-explosive detonation scenarios, which relate to an assessment for a "maximum-credible" accident. This $\mathrm{p}$ - essment does not explicitly include the effects of terrain but does retain the three-dimensional characteristics of the wind field.

While performing the initial assessment, more complete meteorological and source term data bases are developed for the advanced assessment, which is available to the IRF commander within 45 minutes after notification. This assessment, shown in Figures 4 and 5 , is based on the full capability of the MATHEW/ADPIC model. Additional assessments are produced (usually hourly) as long as needed. The projected lung dose due to the inhalation of plutonium particles by individuals exposed to the radioactive cloud (see Fig. 4) assist the IRF on-scene commander with evaluating the potential hazard to the general public until comprehensive radiation measurements and bioussays can be performed. Action levels of $150,25,5$, and $0.5 \mathrm{REM}$ are used to provide general guidance for any protective actions that might be required. Figure 5 illustrates projected surface contamination levels which are used for establishing access to the contaminated areas and for clean-up if required. Action levels of $600,60,6$ and $0.2 \mu \mathrm{Ci} / \mathrm{m}^{2}$ are used for general guidance for ground contamination. Note also that the figures include a 2000 - $\mathrm{ft}$ circle centered on the accident site. It denotes a generic high-explosives fragmentation radius. A distance scale is included on the lower right side of the plot, and the squares situated in the lower left corner of the plot refer to the computational grid size for use by the ARAC assessor for quality control purposes.

These examples illustrate how the ARAC products have been tailored for the user. Assessments of incidents at DOE facilities or nuclear power plants have a different format and require a different interpretation. Experience gained by the ARAC staff over the 


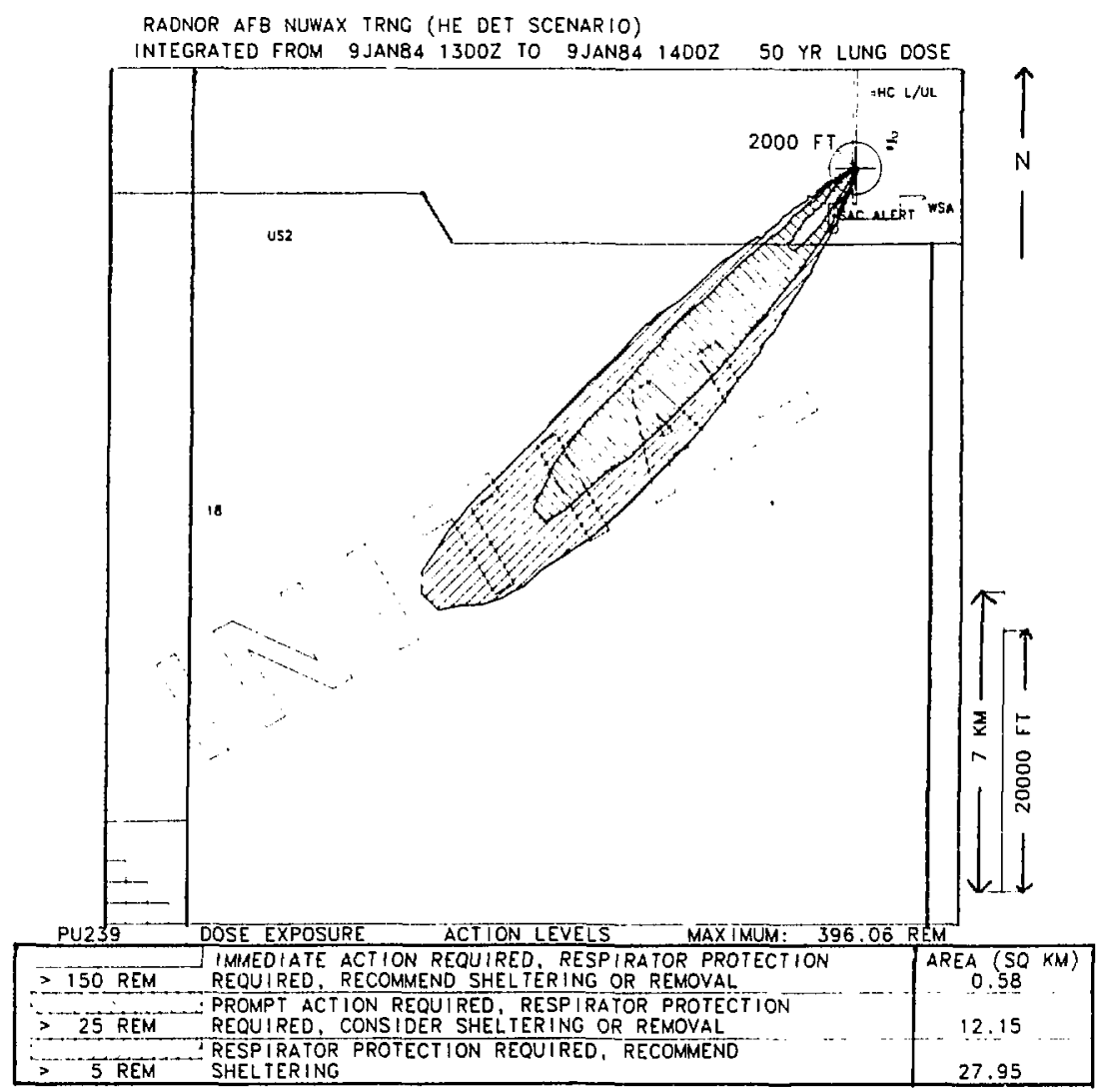

FIGURE 3. Initial MATHEW/ADPIC calculation available to the emergency-response manager in 15 minutes.

past 11 years has shown that the assessment products need to be designed to meet the requirements of the users.

\section{Requirements for Receiving the ARAC Service}

To provide the ARAC services to a facility, several data bases must be prepared. Topographical and geographical information are required to establish the MATHEW/ADPIC model grid on which all the ARAC products are plotted. The standard ARAC site data base is a 200-km-square area centered on the facility of concern. The grid is divided into cells, each $0.5 \mathrm{~km}$ on a side. The terrain elevation of the bottom of each cell is obtained from the U.S. Geological Survey (USGS) digital terrain elevation data products. From this large grid a model subgrid can be generated for any subregion of $40 \times 40$ cells. Figure 6 is an example of the celiular terrain structure on the bottom of the three-dimensional model 


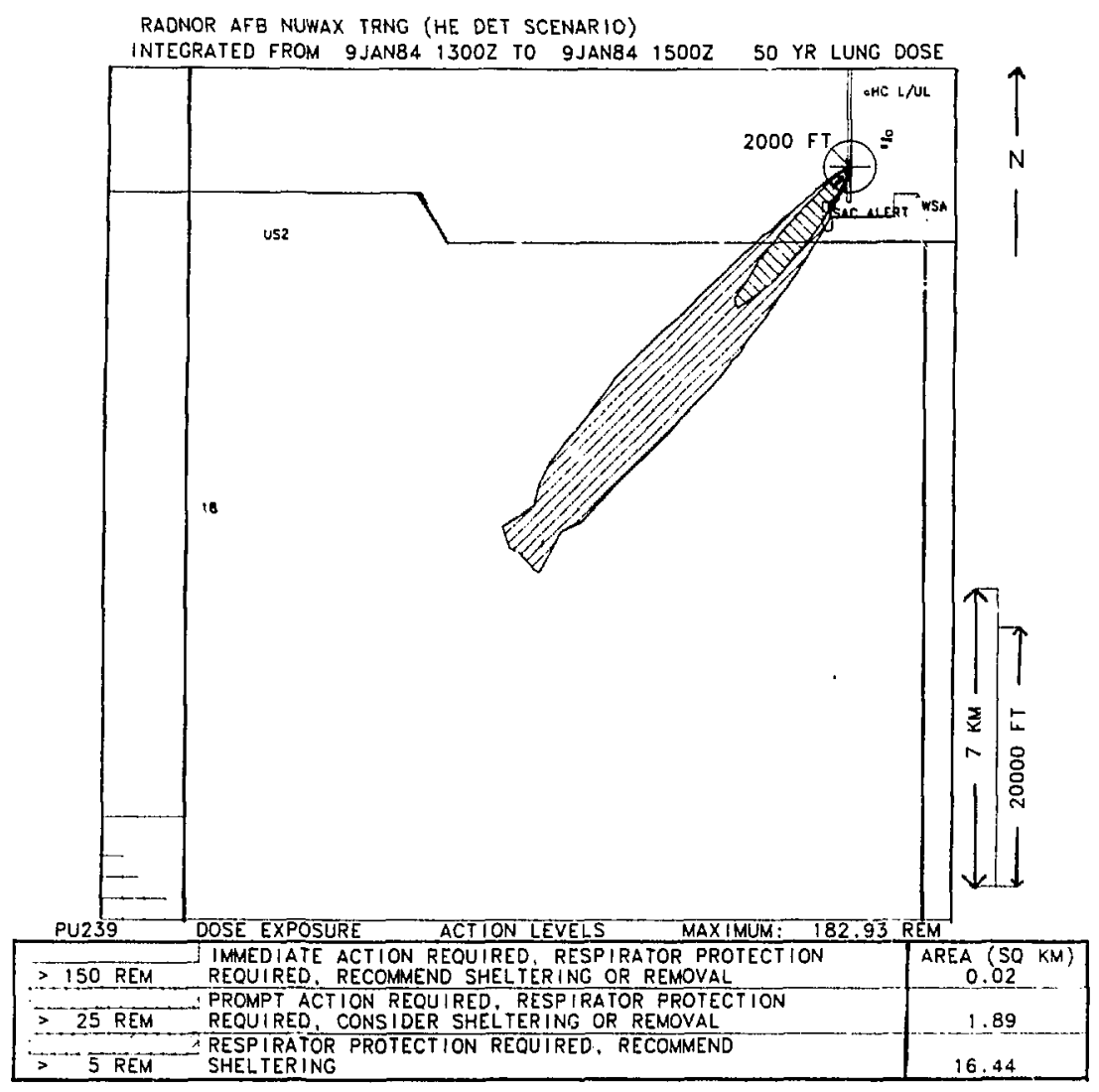

FIGURE 4. Complete MATHEW/ADPIC calculation for projected lung dose available to the emergency response manager in 45 minutes.

grid. Terrain data for the continental U.S. is resident on the ARAC computer system at $0.5 \mathrm{~km}$ resolution. The geographical information (water bodies, rivers and streams, roads and railways, urban areas) and associated names are digitized from the USGS 1:250,000 base maps. More detailed features specific to the facility of concern are taken from local site maps. The geographic features are used for reference points and are displayed on all ARAC plots (e.g., see Fig. 3-5). Once the $200-b y-200 \mathrm{~km}$ master data base is established, any smaller subgrid map may be selected for a particular assessment.

Information is also needed in regard to the facility's operations and handling activities, including the "most probable" and "maximum credible" accident scenarios. This is used to set up "default" model input parameter files. These default files include data related to potential source terms (types of material at, risk, particle size distribution, potential release rates, emission geometry, i.e., release height and stack characteristics, if applicable) as well 


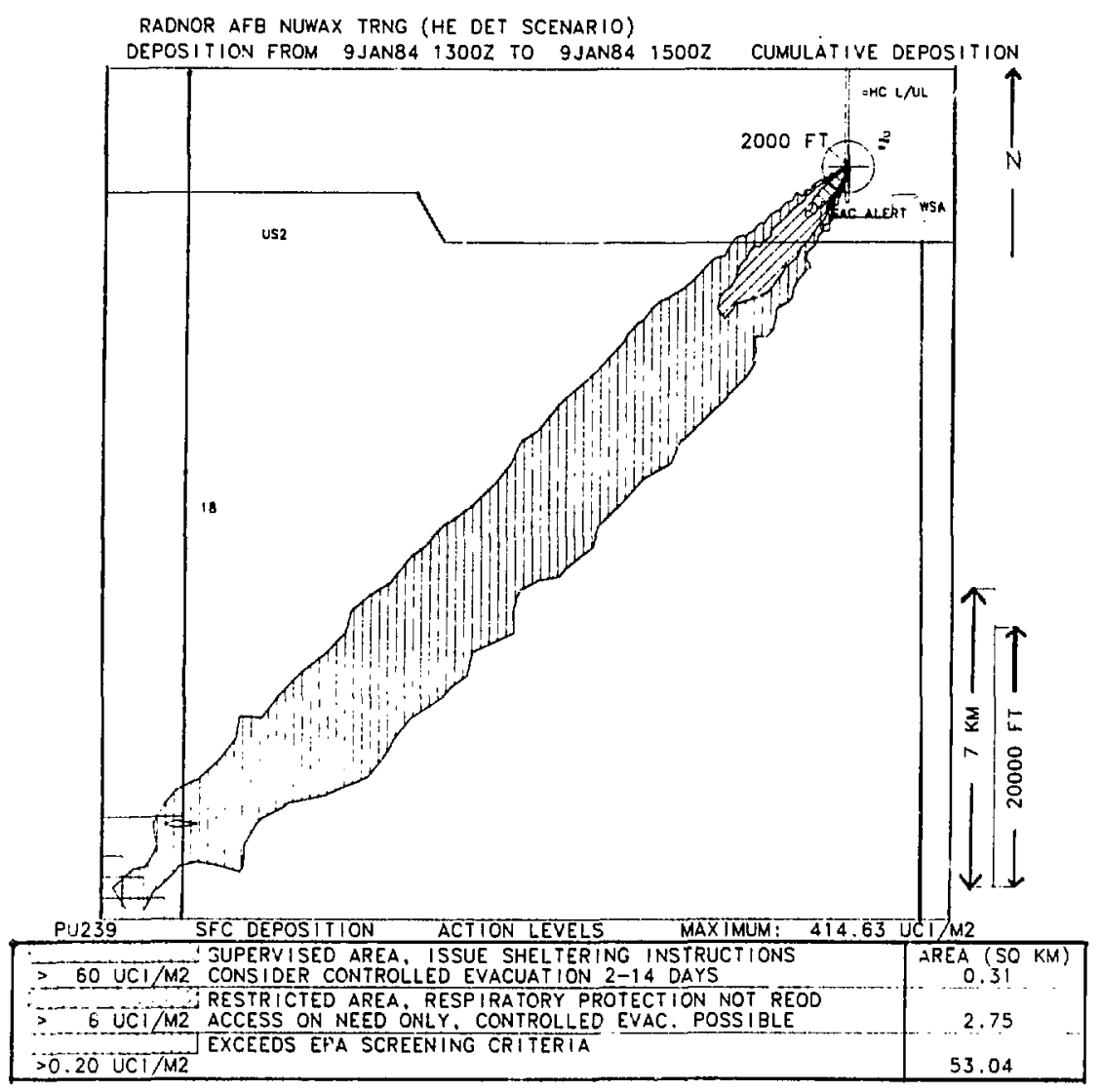

FIGURE 5. Complete MATHEW/ADPIC calculation for ground contamination available to the emergency response manager in $\mathbf{4 5}$ minutes.

as possible accident locations. The location and type of meteorological data available in the immediate vicinity are also included. Whereas ARAC acquires weather data routinely from the AFGWC and the NWS, additional data from air-quality management districts, nearby industries, or local airports may prove very useful during an accident.

For sites judged by the ARAC staff to be deficient in meteorological data coverage, a weather tower needs to be installed at the site. ARAC technicians provide assistance in siting and installation of such a tower, but site personnel are responsible for its operation and maintenance. Towers may be located on or near buildings, as long as the wind flow is representative of the free air flow and is not significantly altered at the sensor height.

The key measurements used by the ARAC models are wind speed and wind direction. While just about any anemometer and wind vane may be used, ARAC has standardized the use of two systems: one manual and one automated. These systems were chosen 


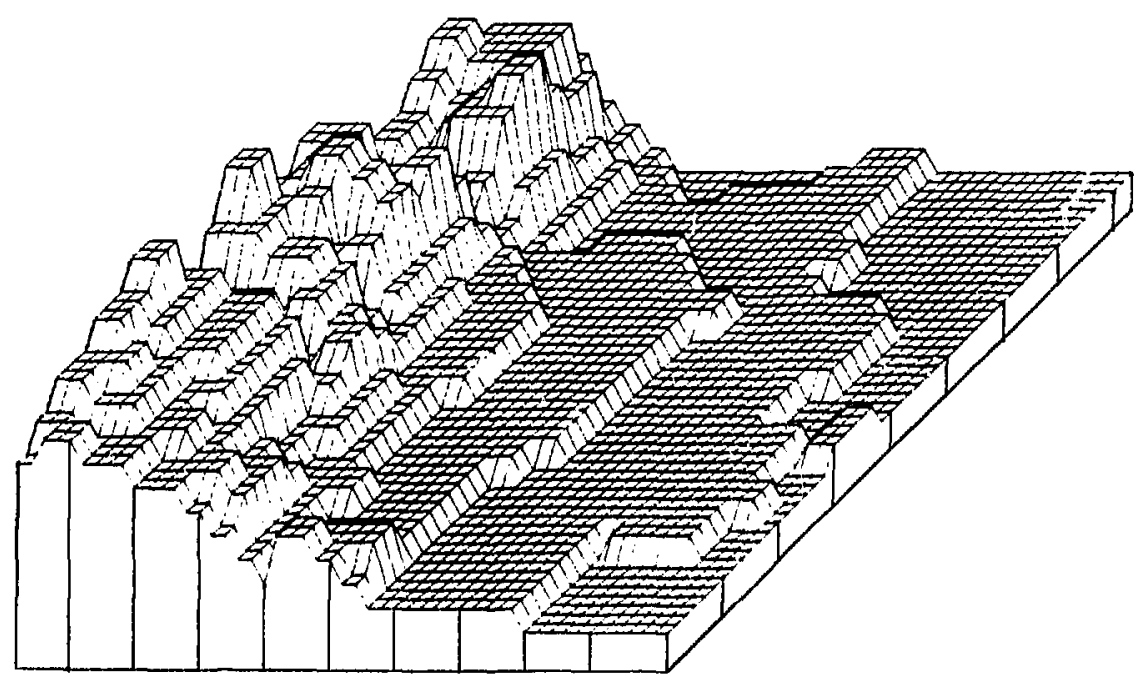

FISURE 6. Example of cellular terrain structure used by the MATHEW/ADPIC model.

because of their sensitive response to low winds, their durability and cost effectiveness. The manual system provides a digital display of date and time, wind speed and direction, indoor and outdoor temperature, and barometric pressure. The measurements are automatically updated on the display once per minute. All values are instantaneous except wind speed, which is averaged over each minute. in order for ARAC to use this data in an accidert situation, it must be resd from the display and manually entered into the ARAC site system or called to the ARAC center over the telephone. This systern, shown in Figure 7, costs under $\$ 500$.

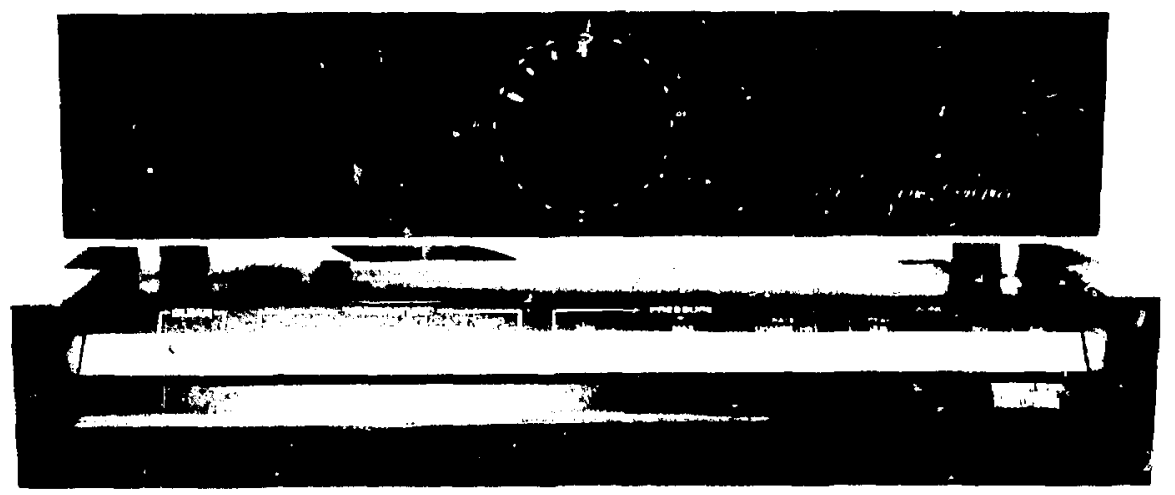

FIGURE 7. Supplemental meteorological data acquisition system. 
The automated meteorological data-acquisition system collects 15-minute-averaged wind velocity and temperature data in a microprocessor at the base of the tower. It has two computer trlephone modems: one is connected to the site system, and the other may be accessed directly from the ARAC center for redundancy. The site system is capable of collecting meteorological data in real time from up to nine levels on each of three separate towers. The standard installation records wind speed, wind gust, wind direction, temperature, and standard deviation of wind direction on each tower level. The $10-\mathrm{m}$, single-measurements-level tower, shown in Fig. 8 costs about $\$ 8,000$ plus installation costs.

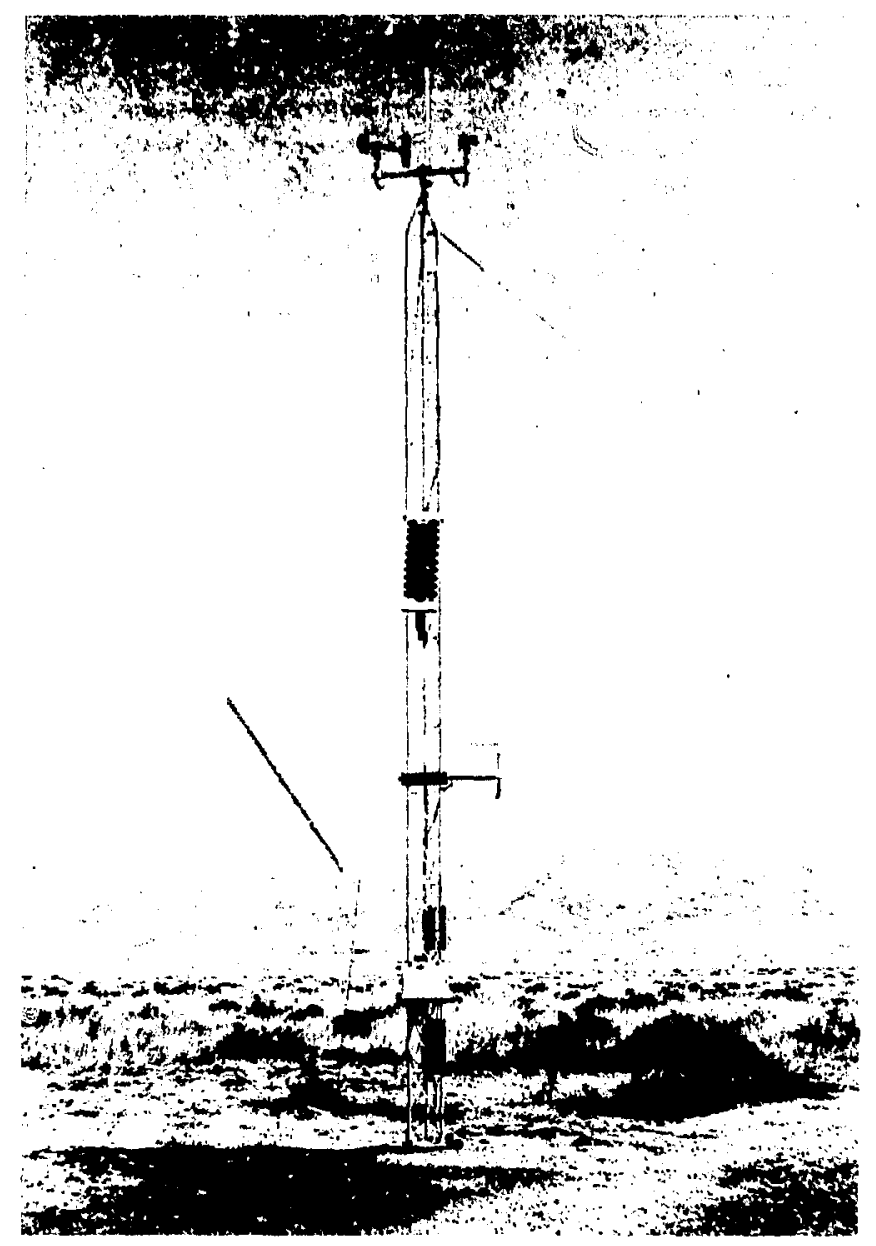

FIGURE 8. Automated meteorological measurements system. 
Training is needed by the site emergency preparedness personnel in order to operate the site system and utilize the ARAC assessments during an emergency. The ARAC staff periodically conducts a two-day training course that provides the foundation and fundamentals of the service. Trainees receive instructions on how an ARAC assessment is made, practice working with ARAC on an example acc:dent (both with and without the use of the site system) and are guided through the interpretation of the ARAC model products. This course is only the beginning of the training program, as ARAC routinely participates in exercises at numerous facilities in order to keep the ARAC services vital and available for an immediate and efficiert response.

\section{Organizations Receiving ARAC Services}

Four federal agencies presently receive direct emergency response support from ARAC and six states have worked with the ARAC service on accidents, exercises, and joint participation projects. Two federal agencies, DOE and DOD Defense Nuclear Agency, are the major users of the service.

The DOE has provided funds for the initial ARAC development and operations for the past 11 years. The service is used for many components of the department that deal with radioactive material. These components are

- Facilities-Lawrence Livermore National Laboratory; Sandia National Laboratory, Livermore; Savannah River Plant; Mound Facility; Rocky Flats Plant and Pantex. Additional facilities are expected to be added to the service in the future.

- Nuclear Emergency Search Team (NEST).

- Accident Response Group (ARG).

- Joint Nuclear Accident Coordinating Center (JNACC).

- Emergency Operations Center (EOC).

- Radiological Asistance Protection (RAP) Offices.

The DOD has largely funded the present expansion of the system and facilities to provide the ARAC service to the following organizations:

- Facilities-Approximately 44 nuclear-capable facilities.

- Major Armed Services Commands.

- National Military Command Center (NMCC).

- Joint Nuclear Accident Coordinating Center (JNACC).

The FAA has used the ARAC service to assess the potential radiation doses to passengers and crews of aircraft flying in or near airborne radioactive material. Originally the service was used in the event of Chinese nuclear weapons tests in the atmosphere; however, ARAC advisories were also issued to the FAA during the TMI accident for aircraft flying in and out of the Harrisburg airport.

In a recent major federal fiold exercise the NRC requested and utilized the ARAC service as an emergency response resource. Since this exercise, plans have evolved to 
include the ARAC service as a resource for the NRC for accidents involving nuclear power plants. Work on this joint effort will continue at a moderate level for the next several years.

The ARAC has worked with the states of New York, California, Pennsylvania, Virginia, Florida, and Texas. A continuing cooperative venture with the state of New York has resulted in the transfer of selected ARAC models to its computer system.[11,12] Most work with the other states has been associated with joint involvement in exercise planning and execution, an activity that is expected to increase in the future.

In addition to providing an emergency response service to U.S. government agencies, the ARAC staff has worked with scientists from several foreign governments to assist in the development of their emergency response plans. This has included the transfer of the ARAC computer modeling and accident-response-system technology, and cooperation on studies of mutual interest. The Italian Ente Nazionale Energie Alternative (ENEA) began working with ARAC personnel in the early 1980's to move the MATHEW/ADPIC computer codes (described in Section 4) to their emergency response computer system. Since that time an ongoing conperative research and technology exchange program has continued at a moderate level.[13] The Japan Atomic Energy Research Institute implemented these computer codes on their emergency response system in 1982.|14] The Swedish National Defense Research Institute moved the codes to one of their facilities in 1983 and more recently the Korean Advanced Energy Research Institute has received copies of these computer codes and is installing them on their computer system. Other studies are ongoing with the United Kingdom, Israel, and Spain.

\section{Future Directions}

In the operations area, sites will continue to be added to the system this year and personnel from each site will attend training courses at LLNL. Exercise participation will continue with the sites and with DOE and DNA headquarters. Installation of site computer systems and meteorological towers will continue. For the remainder of 1985 the major systems development effort will be focused on transferring the MATHEW/ADPIC models from the LLNL computer center to the ARAC computers. This task is expected to be completed during FY-1986. This will permit the ARAC operations staff to become much more involved in exercise participation with each site without causing a severe impact on the LLNL computer center.

The AEROS is capable of being expanded as the needs arise. New data bases may be developed to increase the responsiveness and quality of the system. At the present time a substantial effort is being invested in the development of a continental-scale geographic or base-map data base to match the existing topographic data base. In the future comparable demographic and landuse data bases will be required, particularly as chemical accidents ascend to higher levels of importance with responsible government agencies. Extensive radiological dose conversion-factor data bases are also in the process of development for both the external and internal dose pathways. Comparable data bases need to be developed for the chemical/toxic materials hazards area. Future applications of ARAC may range from biological substance releases to dust clouds produced by volcanic eruptions. Thus, 
the long range goal of ARAC is to provide a national capability for emergency response to a wide range of potential accidental releases of hazardous materials into the atmosphere.

Research will begin on the development of operational time-dependent models for forecasting the wind and temperature fields on the scale of 100 to $200 \mathrm{~km}$. These models will be used to forecast consequences in time ranging from 6-12 h. These models will not replace the present MATHEW diagnostic model; but, rather, they will be used in conjunction with the MATHEW model to improve the ARAC capability to assist emergency-response managers plan protective measures for long-term events or events that involve the incipient release of hazardous miterials.

\section{Acknowledgment}

This work was performed by the Lawrence Livermore National Laboratory under the auspices of the U.S. Department of Energy under contract No. W-7405-Eng-48 and the U.S. Defense Nuclear Agency under IACRO 85-275. 


\section{References}

1. M. H. Dickerson and R. C. Orphan, "Atmospheric Release Advisory Capability," Nuclear Safety, 17, 281-289 (1976).

2. M. H. Dickerson, J. B. Knox, and R. C. Orphan, ARAC Update-1979, Lawrence Livermore National Laboratory Report UCRL-52802, Livermore, CA (1979).

3. M. H. Dickerson, P. H. Gudiksen and T. J. Sullivan, The Atmospheric Release Advisory Capability, Lawrence Livermore National Laboratory Report UCRL-52802-83 (1983).

4. T. J. Sullivan, Modeling, Simulation and Emergency Response, Lawrence Livermore National Laboratory Report UCRL-91263. Presented at the 1985 SCS Multiconference, San Diego, CA, January 24-26, 1985 (1984).

5. R. L. Baskett, "Structured Analysis Techniques Applied to the Design of a National Emergency Response System," presented at the 77th Annual Meeting, San Francisco, CA, 24-29 June 1984, Air Pollution Control Association, Pittsburgh, PA (1984).

6. B. S. Lawver, it Graphics Metafile Interface to ARAC Emergency Response Models for Remote Workstation Study, Lawrence Livermore National Laboratory Report UCRL91261. Presented at the 1985 SCS Multiconference, San Diego, CA, January 24-26, 1985 (1984).

7. H. Walker and P. Weidhaas, "TERRA, \& Raster Graphics Code for Rendering Perspective, Shaded Color Images of Complex Surfaces," preented at the Sixth CUBE Symposium, October 10-12, 1984, Los Alamos National Laboratory, New Mexico (1984).

8. R. Lange, MATHEW/ADPIC Model Evaluation of the 1980 ASCOT Geysers Drainage Flow Experiment, Lawrence Livermore National Laboratory Report UCRL-91854, to be published in Proceedings of the DOE/AMS Model Validation Workshop, October 23-26, 1984, Kiawah Island, SC (1984).

9. K. R. Peterson and R. Lange, An Evaluation and Sensitivity Study of the MATHEW/ ADPIC Models Using EPRI Plains Site Data for a Tall Stack, Lawrence Livermore National Laboratory Report UCRL 91856 (1984).

10. Rodriguez, D. I. and L. C. Rosen, An Evaluation of a Series of $S F_{6}$ Tracer Releases Using the MATHEW/ADPIC Model, Lawrence Livermore National Laboratory Report UCRL-91854 (1984).

11. I. Gotham, B. Krawchuk and J. Matuszek, "The Evaluation of a Computer-Based, Dose Assessment Capability for Nuclear Power Plants in the State of New York," to be presented at the 78th Annual meeting of the Air Pollution Control Association at Detroit, Michigan, June 16-21, 1985.

12. B. Krawchuk, I. Gotham and J. Matuszek, "Computer Graphics to Display Plume Modeling Results for Nuclear Emergency," to be presented at the 78th Annual meeting of the Air Pollution Control Association at Detroit, Michigan, June 16-21, 1985.

13. P. H. Gudiksen, R. Lange, M. H. Dickerson, T. J. Sullivan, L. C. Rosen, H. Walker, G. Boeri, R. Caracciolo and R. Fiorenza, Joint Research and Development on Toxic Material Emergency Response Between ENEA and LLNL: 1982 Progress Report, Lawrence Livermore National Laboratory Report UCRL-53315 (1982). 
14. K. Asai, N. Shinozawa, H. Ishikawa, M. Chio and T. Hagashi, Vectorization of Nuclear Codes for Atmospheric Transport and Exposure Calculation of Radioactive Material, Tokai Research Establishment Report, JAERI-M 82-128 (1982). 


\section{Appendix A. Description of Operational Models}

\section{MATHEW/ADPIC Model}

This three-dimensional coupled transport and particle-diffusion model calculates the transport and diffusion of a puff or a plume in a time-varying atmospheric boundary layer. It is based on the particle-in-cell (PIC) concept, with the hydrodynamic aspect being replaced by a three-dimensional, mass-conservativc, time-varying windfield provided by the MATHEW code. We have used this computer model to simulate particulate and gaseous concentrations, the general deposition of particles with given size distributions, and rainout (from one or more sources) out to distances of several hundred kilometres. This model is presently the cornerstone of the regional assessment area and has been used for over 2000 hours of simulations during the past 8 years.

\section{PATRIC Model}

This three-dinensional, PIC sequential puff code for modeling the trunsport and diffusion of atmospheric pollutants was developed as a simplified and accelerated version of our three-dimensional ADPIC transport and diffusion code. PATRIC has no topography and uses interpolated wini fields to model $24 \mathrm{~h}$ of real time in $1 \mathrm{~min}$ of computer time-a capability that makes the code suitable for annual air-quality assessments. It has been included in the LLNL/ARAC suite of codes for emergency and assessment response. Modified versions of PATRIC have been developed for simulating transport and diffusion of nuclear material for scales of $1000 \mathrm{~km}$ and global.

\section{BPUFF Model}

This two-dimensional, axially symmetric Lagrangian model is used for calculating the anisotropic diffusion of particles or gases in a frame of reference that moves with the center of the cloud of particles or gases. The diffusion coefficients can be time dependent. An Eulerian grid at the eartl's surface keeps track of the cloud's position and provides the framework for calculating air concentrations during its passage.

\section{KDFOC2}

A versatile fallout model has been developed to assess complex civil defense and military effects issues. Large technical and scenario uncertainties require a fast, adaptable, time-dependent model to obtain technically defensible fallout results in complex demographic scenarios.

The KDFOC2 capability, coupled with other data bases available in G-Division provides the essential tools to consider tradeoffs between various plans and features in different nuclear scenarios and to estimate the technical uncertainties in the predictions. 


\section{CPS Model}

This Gaussian, Continuous Point Source (CPS) diffusion and deposition model is used in ARAC applications for first-response calculations. It has two modes of operation: (1) with one set of wind and stability inputs, and (2) with up to one year of $15 \mathrm{~min}$ to $1 \mathrm{~h}$ averages. The model incorporates deposition velocity, plume rise, radioactive decay, terrain, and washout. In the multicard input mode, the user specifies whether the release is routine or accidental. The output consists of probabilities fo: exceeding specified concentration and deposition contours.

\section{IPS Model}

This Gaussian, Instantaneous Point Source (IPS) diffusion and deposition model is in ARAC applications for first-response calculations associated with puff releases. Its features are similar to those in the CPS model. 